To cite this article: Luke A. Adams (2022). SECURITY MANAGEMENT CULTURES AND LECTURERS' ACADEMIC SERVICE DELIVERY IN TERTIARY INSTITUTIONS IN AKWA IBOM STATE, NIGERIA, International Journal of Education and Social Science Research (IJESSR) 5 (1): 64-73

\title{
SECURITY MANAGEMENT CULTURES AND LECTURERS' ACADEMIC SERVICE DELIVERY IN TERTIARY INSTITUTIONS IN AKWA IBOM STATE, NIGERIA
}

\author{
Luke A. Adams (Ph.D. candidate) \\ Department of Educational Management, \\ Faculty of Education, University \\ of Calabar, Calabar, Nigeria
}

DOI: http://dx.doi.org/10.37500/IJESSR.2022.5106

\begin{abstract}
This study examined security management cultures and lecturers' academic service delivery in tertiary institutions in Akwa Ibom State of Nigeria. To achieve this purpose, correlational survey research design was adopted. Stratified and proportionate sampling techniques were used to sample 1,017 (15 percent) from 6,782 lecturers from all the 11 tertiary institutions in the State to participate in the study. Two research questions were raised and two hypotheses formulated to guide the study. Data collection was carried out with the use of researchers' constructed instrument of 20-items titled: Security Management Cultures and Lecturers' Academic Service Delivery Questionnaire (SMCLASDQ). The instrument was validated by experts in Measurement and Evaluation and Educational Management, and reliability was established through Cronbach Alpha analysis which yielded .90, hence indicating high internal consistency in achieving the purpose of this study. Data collected were analyzed using Pearson's Product Moment Correlation Analysis. Results obtained revealed that information security culture and physical security cultures significantly related with lecturers' academic service delivery. It was concluded that security management cultures in terms of information and physical security management cultures are correlates of lecturers' academic service delivery in tertiary institutions in Akwa Ibom State of Nigeria. Based on the findings and discussions, it was recommended among others that the school management and government should endeavour to improve security management cultures in terms of curbing cult-related activities, kidnapping, drug abuse/offences, room break-in, stealing and pilfering and sexual assaults in order to promote a safe school environment for lecturers' effective service delivery in the institutions in the State.
\end{abstract}

KEYWORDS: Security, Management, Culture, Lecturers, Service, Delivery, Tertiary Institutions

\section{INTRODUCTION}

Globally, tertiary education institutions for ages have been fraught with ubiquitous issues and security challenges. These issues and challenges range from poor service delivery of staff, insecurities, cultism, fighting and abduction, among others. In most instances, these ugly scenarios might usually leave temporary or permanent marks on the perpetrators and schools setting. They may also disrupt the 
school programmes and truncate the service delivery of lecturers thus making the actualization of the philosophy, vision and mission for which the institutions are established very difficult.

The Design-Based Research Collective in Akuegwu and Nwi-ue (2016) conceive academic service delivery as a teaching method which promotes student learning through active participation in meaningfully planned services ranging from the school community to course content in tertiary institutions. These services among others include research, community service, teaching, students' assessment and project supervision. Teaching delivery is a systematic and interactive process by which a teacher imparts knowledge and skills to the learners (Uzoigwe, 2021). Students' assessment is the methodical process of measuring the degree to which the instructional objectives have been achieved by the learners. Project supervision is the systematic process by which a lecturer lends professional guidance to a student during his period of research. Teaching service delivery connotes both assessment and supervision of students' academic activities. It equally entails the creation, transmission, control and evaluation of knowledge with the purpose of ascertaining its authenticity in impacting the cognitive, affective and psychomotor domains of the learner (Uzoigwe, 2021). According to the Federal Republic of Nigeria (2014) tertiary education is designed to contribute to national development through high level manpower training who would be relevant to the needs of the labour market. It is also structured to provide accessible and affordable quality learning opportunities in formal and informal education in response to the aspirations and interests of all. With these lofty goals, the standards expected of academic service delivery in tertiary institutes must be of quality at different stages and that the learning tasks and the assessment of teaching and learning are in alignment (Clarke \& Mayer, 2017). There must also be a clear objective of academic service delivery in promoting scholarship, entrepreneurship and community service using academics as the medium (FRN, 2014).

Unfortunately, in spite of their crucial roles as course designers and as lecturers, the rate of poor academic service delivery among academics in Akwa Ibom State tertiary institutions is alarming. Some academic staff do not seem to design tasks that offer opportunities to be successful but also challenge students. They appear not to provide stimulating and interesting activities, and materials, including some novelty and variety in tasks and learning activities. There is lack of clear and accurate feedback regarding competence and self-efficacy, focusing on the development of expertise and skill. Some lecturers hardly build supportive and caring personal relationships in the community of learners. Some academic staff do not use task, reward and evaluation structures that promote mastery, learning, effort and understanding course and lecture content in teaching. They do not ensure that course design, selection of teaching and learning opportunities and assessment help the students to learn in order to produce graduates of higher education capable of critical thought, able to be creative and innovate at a relatively high level. Regarding poor academic service delivery, Biggs (2021) points out that students' approaches to study and their motives are determined by a number of aspects of the higher education system, including their perception of the Departmental quality and university they are in, and even of the university system in general. This simply reinforces the idea that if poor academic 
service delivery is left untamed in tertiary institutions, it may likely promote mediocrity, even in those students initially striving for more learning.

Worried about academic staff poor service delivery in tertiary institutions, the United Nations (2019) identified some of the causes to include poor accommodation, lack of office spaces, incessant industrial action, and instability in government policies, poor organisational behaviour. Others are politicized accreditation services, lack of curriculum development programmes, insufficient good textbooks, and low motivation, decline in staff quality and quantity, poor university governance, deficient inputs, increasing class size and inadequate financing, negative influence of Departmental cultures, deterioration of quality assurance practices, and poor security management culture in the university system, to mention but a few.

Security management culture is a way of protecting lives and properties of a group of people including the behaviours, beliefs, values, and symbols that they accept and are passed along from one generation to the next. One of the dimensions of security management cultures that affect lecturers' academic service delivery in tertiary institutions is information security culture. It is the process of defining and managing the information that an organization needs for programme implementation and ensures that it is sensibly protecting the confidentiality, availability, and integrity of assets from threats and vulnerabilities. Buttressing this fact, Harold (2019) found that the academic staff service delivery by way of information qualities, maturity level of information security management processes and performance are directly related. This shows that mastering security information management process is crucial for an enterprise because it greatly contributes to organizational performance, improves the information system support among others. Unfortunately, Shehade and Nazem (2013) found that there is an impact of networks, individuals and procedures, and management information system as a whole, security hardware and software equipment on the performance of governmental organizations. On the other hand, Harrell (2014) found that the relationships between the structure, technology, task and people constructs could have an impact on user information security behavior. It was also found that a change in the organization's information security policies, technology, or a change in employee processes for task completion could impact a user's information security choice. Some of the information security situations found in the school premises could be easily changed to lower the risk of a user's choice to circumvent information security. This change could be a technical configuration change or a purchase of a new technology or a change in a process to help impact a user's choice to circumvent information security controls in the school.

Liene (2020) submitted that formal norm on information security without proper maintenance and awareness does not impact employee service delivery.

Another dimension of security management culture which can affect academic staff service delivery is physical security culture. Lecturers are bound to experience poor service delivery in a school system when there is physical attack and lack of adequate and regular training for security personnel to cope 
with the advanced level of criminality that is on the increase in university campuses (Beard, 2010). Correspondingly, Nwaobodo and Udebunu (2018) found that the available security devices predicted the improvement of security in most public schools sampled for the study. Also, the emergency response plans for managing safety threats in most public schools were not adequately available and the respondents did not agree on the adequacy of all the items on security measures that should be adopted in managing school physical security. This implies that these security devices are needed to check the level of insecurity threatening and causing danger and disaster in the learning environment for staff service delivery. Unfortunately, it is observed that most of the security personnel in Akwa Ibom State do not have formal training on physical security management services and are therefore unable to operate modern security gadgets with efficiency. Also, according to Badiora in Ekpoh, Aniefiok and Ukpong (2020), the spectra of crimes on some campuses of tertiary institutions in Nigeria have grown to an alarming rate that it has remained a permanent issue in national discourse. Unfortunately, this has adversely affected the academic and social life of both staff and students on campus. These waves of crises have brought additional responsibilities for the school authorities to provide adequate security. In the past, security officers were expected to be reactive - checking on potential risks and responding when something happened. However, as observed by Rosenbery in Ekpoh, Aniefiok and Ukpong (2020), a security officer is an integral, proactive part for creating a safe environment, preparing for all hazards, as well as, actively promoting a safer place to study, work and visit. Perhaps the most dramatic paradigm shift in security operations is the change from security officers being behind-the-scene enforcers and responders, to serving as collaborative promoters of the college's culture. In corroboration, Beard (2010) noted that an open and proactive approach to identifying and mitigating risk is crucial in building a safety culture in which members' perceptions are positive. In the same vein, Lawrence (2017) posited that school security has changed, requiring well-developed security and safety plans, as well as, proper risk management, together with wellarticulated strategies and procedures to protect schools from crimes and threats. Others found that management of physical security culture safe school planning and essential components of comprehensive crisis management plan significantly related to academic staff service delivery (Brian and Douglas, 2018). This implies that physical security management entails the best practices in schools that have to do with developed, implemented, or evaluated practices and policies of security and crisis preparedness for maintaining an effective learning environment. It is against this background that the researcher is poised to find out the extent to which security management cultures relate to lecturers' academic service delivery in tertiary institutions in Akwa Ibom State of Nigeria.

\section{Statement of the problem}

Akwa Ibom State tertiary institutions are established by law to render social services to students/staff and communities. But a critical observation by the researcher shows that over the years, the quality of academic service delivery in tertiary institutions in Akwa Ibom State has left much to be desired. Some lecturers seem not to render their services in ways that are informative, interesting and engaging when it comes to teaching delivery, students' assessment and project supervision. There appears that some academic staff do not effectively structure their lecture content with clear objectives to stimulate 
students' interest towards learning. Some lecturers cannot establish a positive classroom environment with disciplinary measures for effective teaching and learning. It seems that some academic staff do not organise their materials in a way students can understand the development of the argument or the logic in the ordering of the information or ideas. There are observable delays in completion of research project/thesis/dissertations writing and defense owing to students' dissatisfaction with the supervision processes and poor student-supervisor relationships.

Academic staff poor service delivery has degenerated to delay in releasing students' results, prolonging graduation periods for final year students and denying students their right of knowledge of their academic standing at the end of the semester or session. Worse still, the conduct of assessment to measure academic progress in some cases has been strictly confined to the dictates of students. These anomalies have culminated to students' examination failures, course carry overs and involvement in examination malpractices, probations, skipping of class assignment/group work, poor concentration, irregular attendance to classes, missing examinations, dropout of school, prolonging prescribed maximum course duration, and other attendant academic deficiencies.

However, poor academic service delivery among lecturers is unacceptable because it contributes in bringing down the prestige of the tertiary institutions and limiting it from achieving its mandate. The Government and other NGOs in an attempt to improve academic service delivery organized Information and Communication Technology (ICT) retraining and quality assurance programmes for lecturers among others. Yet the problem of academic staff service delivery persists as it has affected the quality of graduates produced from tertiary institutions yearly, as well as the economic productivity of Nigeria in general. On the contrary, it is likely that poor security management culture might be the contributing factor to poor service delivery of lecturers in Akwa Ibom State. Therefore, this study is set to addressing this question: To what extent does security management culture correlate with lecturers' service delivery in tertiary institutions in Akwa Ibom State, Nigeria?

\section{Purpose of the study}

The study investigated security management cultures and lecturers' academic service delivery in tertiary institutions in Akwa Ibom State, Nigeria. Specifically, the study sought to find out whether:

1) Information security culture relates to lecturers' service academic delivery in tertiary institutions in Akwa Ibom State, Nigeria

2) Physical security culture relates to lecturers' academic service delivery in tertiary institutions in Akwa Ibom State, Nigeria

\section{Research questions}

The following questions were raised to guide the study

1) To what extent does information security culture relates to lecturers' academic service delivery in tertiary institutions in Akwa Ibom State, Nigeria? 
2) To what extent does physical security culture relate to lecturers' academic service delivery in tertiary institutions in Akwa Ibom State, Nigeria?

\section{Research hypotheses}

The following hypotheses were formulated to guide the study

1) Information security culture does not significantly relate to lecturers' academic service delivery in tertiary institutions in Akwa Ibom State, Nigeria.

2) Physical security culture does not significantly relate to lecturers' academic service delivery in tertiary institutions in Akwa Ibom State, Nigeria.

\section{Methodology}

This research was carried out in Akwa Ibom State, Nigeria. This study area was chosen because it is believed to be fraught with inadequate security personnel, insufficient patrol vehicles, poor lighting of university environments, non-availability of modern security facilities, poor funding of security departments, porous campus environments, lack of security-awareness education, non-availability of electronic gadgets among others factors militating against effective security checks in the tertiary institutions. This study adopted survey research design. This was because the design allowed the researcher to sample the opinions of respondents through the use of questionnaire, describe and interpret the findings based on the information obtained from the sample. This design was chosen to examine how investigated security management cultures and lecturers' service delivery in tertiary institutions in Akwa Ibom State, Nigeria. The population of the study consisted of all the 6,782 lecturers in tertiary institutions in the State. Stratified and proportionate sampling techniques were used to sample 1,017 (15 percent) of the population for the study. A 20-item questionnaire designed on a four-point modified Likert scale and titled: Security Management Cultures and Lecturers' Academic Service Delivery Questionnaire (SMCLASDQ) was used to elicit information from the respondents. The instrument was validated by experts in Measurement and Evaluation as well as Educational Management. The reliability index of 0.90 was established using Cronbach alpha analysis. This value was considered appropriate for the instrument to be used for the study. Data obtained were analysed using Pearson Product Moment Correlation Statistics.

Hypothesis one: Information security culture does not significantly relate to lecturers' academic service delivery in tertiary institutions in Akwa Ibom State, Nigeria. 
Vol. 5, Issue.1, Jan-Feb 2022, p no. 64-73

Table 1 Pearson product moment correlation analysis of the relationship between information security culture and lecturers' service delivery in terms of teaching delivery, students' assessment and project supervision $(\mathrm{N}=1,017)$

\begin{tabular}{lllllll}
\hline Variables & N & Mean & S.D & Df & r-cal & p-val \\
& & & & & & \\
& & & & & \\
Information security culture $\left(\mathrm{X}_{1}\right)$ & 1,017 & 13.6951 & 2.30362 & & & \\
Teaching delivery $\left(\mathrm{Y}_{1}\right)$ & 1,017 & 12.0041 & 2.49162 & 1,015 & $.489 *$ & .000 \\
Students' assessment $\left(\mathrm{Y}_{2}\right)$ & 1,017 & 12.2398 & 2.74111 & 1,015 & $.403 *$ & .000 \\
Project supervision $\left(\mathrm{Y}_{3}\right)$ & 1,017 & 11.6260 & 3.68316 & 1,015 & $.289 *$ & .000 \\
\hline
\end{tabular}

$*>.05$, critical=. 159 .

The independent variable in this hypothesis is information security culture while the dependent variable is lecturers' service delivery assessed from three perspectives which are teaching delivery, students' assessment and project supervision. The variables were measured continuously. To test this hypothesis, Pearson product moment correlation was used and the result showed that for information security culture and teaching delivery $\left(r=.489^{*}, p>.05\right)$, for information security culture and students' assessment $\left(\mathrm{r}=.403^{*}, \mathrm{p}<.05\right)$ and for information security culture and project supervision $\left(\mathrm{r}=.289^{*}\right.$, $\mathrm{p}<.05)$. A cursory look at the p-values shows that $\mathrm{p}(.000)$ is less than $\mathrm{p}(.05)$ for the three dimensions. This implies that there is a significant relationship between information security culture and lecturers' service delivery for the three dimensions assessed. Hence, the null hypothesis is rejected and the alternate retained.

Hypothesis two: Physical security culture does not significantly relate to lecturers' service delivery in tertiary institutions in Akwa Ibom State, Nigeria.

Table 2

Pearson product moment correlation analysis of the relationship between physical security culture and lecturers' service delivery in terms of teaching delivery, students' assessment and project supervision $(\mathrm{N}=1,017)$

\begin{tabular}{lrrrrrr}
\hline Variables & $\mathbf{N}$ & Mean & Std. Dev & df & r-cal & p-val \\
\hline Physical security culture $\left(\mathrm{X}_{2}\right)$ & 1,017 & 12.1260 & 2.57388 & & & \\
Teaching delivery $\left(\mathrm{Y}_{1}\right)$ & 1,017 & 12.0041 & 2.49162 & 1,015 & $.411^{*}$ & .000 \\
Students' assessment $\left(\mathrm{Y}_{2}\right)$ & 1,017 & 12.2398 & 2.74111 & 1,015 & $.373^{*}$ & .000 \\
Project supervision $\left(\mathrm{Y}_{3}\right)$ & 1,017 & 11.6260 & 3.68316 & 1,015 & $.171^{*}$ & .004 \\
\hline
\end{tabular}

$*>.05$, critical $=.159$ 
The independent variable in this hypothesis is physical security culture while the dependent variable is lecturers' service delivery assessed from three perspectives which are teaching delivery, students' assessment and project supervision. The variables were measured continuously. To test this hypothesis, Pearson product moment correlation was used and the result showed that for physical security culture and teaching delivery $\left(\mathrm{r}=.411^{*}, \mathrm{p}<.05\right)$, for physical security culture and students' assessment $\left(\mathrm{r}=.373^{*}, \mathrm{p}<.05\right)$ and for physical security culture and project supervision $\left(\mathrm{r}=.171^{*}, \mathrm{p}<.05\right)$. A cursory look at the p-values shows that $\mathrm{p}(.000)$ is less than $\mathrm{p}(.05)$ for the three dimension. This implies that there is a significant relationship between physical security culture and lecturers' service delivery for the three dimensions assessed. Hence, the null hypothesis is rejected and the alternate retained.

\section{Discussion of findings}

One of the findings of the study revealed that there is a significant relationship between information security culture and lecturers' service delivery for the three dimensions assessed. This finding implies that the effective service delivery of lecturers is a function of the high extent of information security culture in the tertiary institutions. This finding is in line with that of Harold (2019) who found that the academic staff service delivery by way of information qualities, maturity level of information security management processes and performance are directly related. The finding is also in line with that of Shehade and Nazem (2013) who found that there is an impact of networks, individuals and procedures, and management information system as a whole, security hardware and software equipment on the performance of governmental organizations. It is also in tandem with Harrell (2014) who found that the relationships between the structure, technology, task and people constructs could have an impact on user information security behavior. This shows that mastering security information management process is crucial for a tertiary institution because it greatly contributes to school organizational performance, improves the information system support among others. Another finding of this study showed that there is a significant relationship between physical security culture and lecturers' service delivery for the three dimensions assessed. This finding implies that the more attention given to physical security checks would likely promote lecturers academic service delivery. This finding is in line with that of Nwaobodo and Udebunu (2018) who found that the available security devices predicted the improvement of security in most public schools sampled for the study. This implies that these security devices are needed to check the level of insecurity threatening and causing danger and disaster in the learning environment for staff service delivery. However, as observed by Rosenbery in Ekpoh, Aniefiok and Ukpong (2020), a security officer is an integral, proactive part for creating a safe environment, preparing for all hazards, as well as, actively promoting a safer place to study, work and visit.

\section{CONCLUSION}

Based on the findings and discussion of this study, it was concluded that security management cultures in terms of information and physical securities are correlates of lecturers' academic service delivery in Akwa Ibom State of Nigeria. 
Vol. 5, Issue.1, Jan-Feb 2022, p no. 64-73

\section{Recommendations}

Based on the findings of the study, the following recommendations were made:

1. The school management should take the issue of security management culture as a matter of priority and so allocate money for the purchasing of such safety and security building equipment as video surveillance (CCTV) among others to enhance lecturers' academic service delivery.

2. Also, school management should provide clear and appropriate measures for managing the information safety and security of school documents. This can be achieved through seminars and workshops and provision of intervention funds by the government to school management.

\section{REFERENCES}

Akuegwu, B. A. \& Nwi-ue, F. D. (2013). Application of Knowledge Management Skills in University Administration in Nigeria: Evidence from Heads of Departments. British Journal of Education, Society \& Behavioural Science, 3(4), 574-588.

Beard, N. U. (2010). School safety, security, and emergency preparedness.www.nsba.org

Biggs, R. T. (2021). A holistic approach to safety and security at schools in South Africa. Mediterranean Journal of Social Sciences, 5(20), 1580-1589

Brian, C. A. \& Douglas, A. D. (2018). Institutional critical factors in university personnel security. International Journal of Innovative Business Strategies (IJIBS). 4 (2), 219-227.

Clarke, E. R. \& Mayer, P. L. (2017). Combating security challenges in the university system. Paper presented at National Conference of Nigerian Universities professional Administrators CANUPA, 2016

Ekpoh, U. I., Aniefiok, O. E. \& Ukpong, N. N. (2020). Security challenges in Universities: Implications for safe school environment. Journal of Educational and Social Research, 10(6), 112-124.

Federal Republic of Nigeria (2014). National Policy on Education. Lagos. NERDC press.

Harold, I. D. (2019). Campus security and safety models: Statistical empirical analysis from a Ghana tertiary institution. Journal of Education and Practice, 10(12), 52-60.

Harrell, U. S. (2014). . Security challenges in educational institutions: The way forward, a paper presented at annual lecture of Zaria Education Development Association (ZEDA). On Friday 27th December, 2013. 


\section{International Journal of Education and Social Science Research}

ISSN 2581-5148

Vol. 5, Issue.1, Jan-Feb 2022, p no. 64-73

Lawrence, P. L. (2017). Security challenges and management strategies in public secondary schools in Aba Education Zone of Abia State. Journal of Economics and Environmental Education, 3(1), 95-104.

Liene, I. O. (2020). School security problems and ways of tackling them. Procedia Social and Behavioral Sciences, 2, 5377-5383.

Nwaobodo, U. Y. \& Udebunu, N. M. (2018). Loose connections: Crime and policing on university campus. The Canadian Journal of Higher Education, XXVII (1), 41-68.

Shehade, I. U. \& Nazem, N. E. (2013). Safety in schools: Matters arising. Vanguard Retrieved from https://www.vanguardngr.com/2015/10/safety-in-schools-matters-arising.

United Nations (2019). The Higher Education Sustainability Initiative (HESI). Harper and Row. USA.

Uzoigwe, M. C. (2021). Management of educational support services and sustainability of public University education programmes in Ebonyi State, Nigeria. An unpublished Ph.D Thesis submitted to Graduate School, University of Calabar, Calabar, Nigeria. 